\title{
IS EXCESSIVE SELF-CRITICISM AND INADEQUATE SELF-COMPASSION HURTING THE WELL-BEING OF FUTURE DOCTORS?
}

\author{
Harshavardhan Sampath1, Debjyoti Das², Geeta Soohinda³, Sanjiba Dutta ${ }^{4}$
}

${ }^{1}$ Associate Professor, Department of Psychiatry, Sikkim Manipal Institute of Medical Sciences, Sikkim Manipal University, Sikkim, India. 2MBBS Final Year, Sikkim Manipal Institute of Medical Sciences, Sikkim Manipal University, Sikkim, India.

${ }^{3}$ Associate Professor, Department of Psychiatry, Sikkim Manipal Institute of Medical Sciences, Sikkim Manipal University, Sikkim, India. ${ }^{4}$ Professor and HOD, Department of Psychiatry, Sikkim Manipal Institute of Medical Sciences, Sikkim Manipal University, Sikkim, India. ABSTRACT

\section{BACKGROUND}

Doctors shoulder enormous levels of responsibility for human lives. This places them at risk of being too critical of themselves, a trait encouraged right from medical school. This self-critical nature, however, has negative psychological consequences. Selfcompassion, the opposite trait of self-criticism, involves treating oneself with kindness and empathy when confronted with failures. It has been shown to enhance interpersonal relationships and well-being.

\section{METHODS}

We aimed to explore the traits of self-criticism and self-compassion among medical students and to analyse how these traits contribute to their psychological health. This is a cross-sectional study on undergraduate medical college students who provided their informed consent. Validated rating instruments were used to assess self-criticism (self-criticizing, attacking and selfreassuring scale), self-compassion (self-compassion scale), psychopathology (depression, anxiety \& stress scale), social relations (network of relationships questionnaire), and psychological well-being (Ryff Scale).

\section{RESULTS}

152 medical students participated in the study. Multiple regression analysis showed that self-criticism $(\beta=-3.01, T$-value $=-2.29, p$ $=0.023)$, self-compassion $(\beta=8.01, \mathrm{~T}$-value $=4.66, \mathrm{p}=0.000)$, and support from friends $(\beta=3.48, \mathrm{~T}$ value $=4.66, \mathrm{p}=0.000)$ significantly predicted psychological well-being among medical students.

\section{CONCLUSIONS}

Self-compassion is an integral trait that can counter pathological self-criticism that has pervaded the medical profession. Students in training need to develop more self-compassion to enhance their resilience when faced with the challenges of a medical career. Mindfulness training has the potential to enhance self-compassion and could be formally included in the MBBS curriculum to enhance the PWB of medical students.

\section{KEY WORDS}

Self Compassion, Psychopathology, Well-Being HOW TO CITE THIS ARTICLE: Sampath H, Das D, Soohinda G, et al. Is excessive self-criticism and inadequate self-compassion hurting the well-being of future doctors? J. Evolution Med. Dent. Sci. 2019;8(30):2385-2388, DOI: 10.14260/jemds/2019/522

\section{BACKGROUND}

Doctors tend to experience high levels of work-related stress. ${ }^{1}$ Occupational stress levels typically begin in the early years of medical college and peaks during the final years of training. ${ }^{2}$ While most students cope with a stressful medical career, a significant minority experience deleterious effects. Thus it is imperative that we identify individuals who are at increased risk for stress early in their medical career. This can enable appropriate preventive strategies to be implemented to enable vulnerable medical graduates to face the challenges of a life in medicine. The traits of self-criticism and self-compassion, as risk and resilience factors for wellbeing deserve attention in this context.

'Financial or Other Competing Interest': None.

Submission 27-05-2019, Peer Review 10-07-2019,

Acceptance 17-07-2019, Published 29-07-2019.

Corresponding Author:

Dr. Harshavardhan Sampath,

Associate Professor,

Department of Psychiatry, Central Referral Hospital,

Sikkim Manipal Campus, $5^{\text {th }}$ Mile, Tadong,

Gangtok-737102, Sikkim, India.

E-mail: drharsha79@yahoo.co.in

DOI: $10.14260 /$ jemds/2019/522
Self-criticism can is a pattern of responding to failure with negative self-judgment. ${ }^{3}$ Self-critical individuals experience exaggerated feelings of unworthiness, inferiority, failure, and guilt. ${ }^{4}$ Self-criticism is a risk factor for many forms of psychopathology. ${ }^{5}$ Blatt et al, reported that high levels of selfcriticism was linked to depressive symptoms. ${ }^{6}$ The very nature of medical career involves experiencing a stressful life events involving failure, criticism and loss which can be daunting to medical students. Self-criticism in fourth-year medical students has been shown to predict depression even years later. ${ }^{7}$ High levels of self-criticism are also common in anxiety disorders, including social anxiety, generalized anxiety, panic, and post-traumatic stress disorder.8-10 Studies have reported the negative effects of a self-critical attitude on interpersonal relationships and peer support. ${ }^{11,12}$

Self-compassion is the polar opposite trait of selfcriticism. Self-compassion involves treating oneself with kindness and empathy when faced with failures and stressful situations. ${ }^{13,14}$ It consists of self-kindness, feeling of common humanity and mindfulness. Self-compassionate people engage in meta-cognitive processing of inner experiences that allows them to relate their experience with others, thus transcending self-absorption and over-identification which reduces separation and loneliness. This allows them to see 
their personal sufferings in a larger and clearer perspective. ${ }^{14}$ Self-compassion is strongly associated with positive mental health and lower levels of depression and anxiety. ${ }^{15,16}$ Selfcompassion provides a greater ability to cope with stressful clinical situations. ${ }^{17}$

\section{METHODS}

The present research aimed to study the traits of selfcriticism and self-compassion among a sample of undergraduate medical college students. Its objectives were to assess a) levels of self-criticism and self-compassion, b) psychological well-being (PWB) of MBBS students, c) factors that contribute to their PWB (Including factors like depression, anxiety, stress, and interpersonal relationships).

A cross-sectional study design was chosen to address the objectives. The sample consisted of 152 MBBS students of Sikkim Manipal Institute of Medical Sciences who provided their written informed consent. Sample size was taken based on the convenience of the study. The study was approved by the institutional ethics committee. The following validated self-rated scales/questionnaires were administered-

a. Forms of Self-Criticizing/Attacking and Self-Reassuring Scale: It is a 22- item scale, which measures different ways people react when things go wrong. ${ }^{3}$ Two components assess self-criticism -"inadequate self and "hated self", while one component measures selfreassurance. The responses are given on a 5-point Likert scale (ranging from $0=$ not at all like me, to $4=$ extremely like me). Mean scores from the facets of inadequate self and hated self was used to assess selfcriticism in this study.

b. Self-Compassion Scale (SCS): It consists of 26 items that measures how often people respond to feelings of failure with self-kindness, self-judgment, common humanity, mindfulness, and over-identification. ${ }^{13}$ Responses are given on a 5-point scale from "Almost Never" to "Almost Always". Items representing non-compassionate responses are coded in reverse so that the overall scores measure levels of self-compassion.

c. The Depression, Anxiety \& Stress Scale (DASS-21 item version): It is designed to assess the severity of symptoms of depression, anxiety, and tension (or stress). ${ }^{18}$

d. The Ryff Scales of Psychological Well-Being: It consists of 18 items that assesses PWB in the following facets: selfacceptance, the establishment of quality ties to other, a sense of autonomy in thought and action, the ability to manage complex environments, pursuit of meaningful goals and a sense of purpose in life, continued growth and development as a person. ${ }^{19}$ Higher total scores indicate greater PWB.

e. Network of Relationships Inventory-Social Provisions Version (NRI-SPV) short form: It examines different personal. ${ }^{20}$ For the purpose of this study, friendship social network was assessed. Respondents rate the extent to which friends satisfy their social needs (13 items). Levels of social support (Positive) and negative interaction (Conflict and antagonism) in friendships was measured for the purposes of this study.

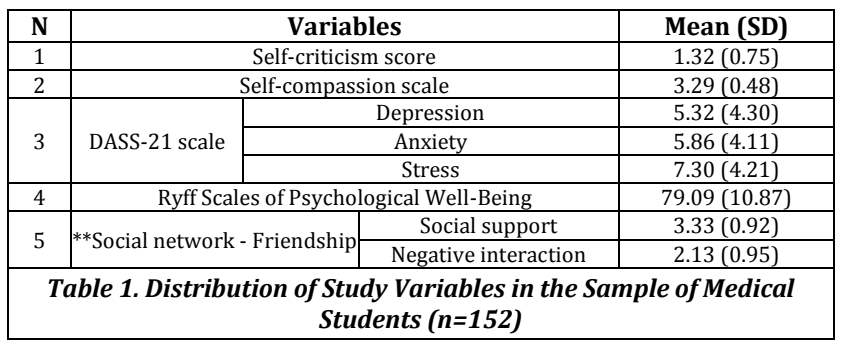

\begin{tabular}{|c|c|c|c|}
\hline \multicolumn{2}{|c|}{$\begin{array}{l}\text { Spearman's Correlation of Variables with Ryff } \\
\text { Scales of Psychological Well-Being }\end{array}$} & Rho & p Value \\
\hline \multicolumn{2}{|c|}{ Self-criticism score } & -0.535 & $0.000^{*}$ \\
\hline \multicolumn{2}{|c|}{ Self-compassion scale } & 0.595 & $0.000^{*}$ \\
\hline \multirow{3}{*}{ DASS-21 scale } & Depression & -0.557 & $0.000^{*}$ \\
\hline & Anxiety & -0.312 & $0.000^{*}$ \\
\hline & Stress & -0.382 & $0.000^{*}$ \\
\hline \multirow{2}{*}{$\begin{array}{l}\text { Social network - } \\
\text { Friendship }\end{array}$} & Support & 0.487 & $0.000^{*}$ \\
\hline & Negative interaction & -0.083 & 0.314 \\
\hline \multicolumn{4}{|c|}{$\begin{array}{c}\text { Table 2. Correlation Matrix Showing Relationship Between } \\
\text { Psychological Well-Being \& Study Variables }\end{array}$} \\
\hline \multicolumn{4}{|c|}{${ }^{*}$ p values $<0.05$ are statistically significant. } \\
\hline
\end{tabular}

\begin{tabular}{|c|c|c|c|c|c|c|}
\hline \multicolumn{2}{|c|}{ Source } & DF & Adj SS & Adj MS & $\mathbf{F}$ & p Value \\
\hline \multicolumn{2}{|c|}{ Regression } & 7 & 9178.0 & 1311.14 & 21.70 & $0.000^{*}$ \\
\hline \multicolumn{2}{|c|}{ Self-criticism } & 1 & 317.2 & 317.21 & 5.25 & $0.023^{*}$ \\
\hline \multicolumn{2}{|c|}{ Self-compassion scale } & 1 & 1312.3 & 1312.33 & 21.72 & $0.000^{*}$ \\
\hline \multirow{3}{*}{ DASS-21 scale } & Depression & 1 & 169.4 & 169.44 & 2.80 & 0.096 \\
\hline & Anxiety & 1 & 2.3 & 2.29 & 0.04 & 0.846 \\
\hline & Stress & 1 & 46.8 & 46.84 & 0.78 & 0.380 \\
\hline \multirow{2}{*}{$\begin{array}{l}\text { Social network - } \\
\text { Friendship }\end{array}$} & Support & 1 & 1311.2 & 1311.19 & 21.70 & $0.000^{*}$ \\
\hline & $\begin{array}{l}\text { Negative } \\
\text { interaction }\end{array}$ & 1 & 23.7 & 23.73 & 0.39 & 0.532 \\
\hline \multicolumn{2}{|c|}{ Error } & 143 & 8640.5 & 60.42 & & \\
\hline
\end{tabular}

Table 3. ANOVA of Psychological Well-Being Versus the Predictor
Variables

\section{Statistical Analysis}

Data analysis was performed using the MINITAB 17 statistical software. ${ }^{21}$ Mean, standard deviation and percentages were used to display data. Spearman's rank correlation was used to analyze the correlation between the individual study variables with PWB. Multiple regression analysis was used to quantify the relative contribution of variables to PWB of medical students.

\section{RESULTS}

152 MBBS students participated in the study. $75.66 \%$ $(n=115)$ were females. The distribution of study variables among MBBS students is illustrated in Table 1.

Male students had significantly higher levels of selfcriticism $(95 \% \mathrm{CI}$ for difference $=0.266-0.857$, T-value $=$ $3.81, \mathrm{p}=0.000)$ and lower levels of self-compassion $(95 \% \mathrm{CI}$ for difference $=0.149-0.4753, \mathrm{~T}$-value $=3.81, \mathrm{p}=0.000$ ) compared to female students (Students t-test).Spearman's correlation (PWB scores were not normally distributed) showed that levels of self-criticism, depression, anxiety and stress had a significant negative correlation, while selfcompassion and friendship support had a significant positive correlation with PWB. (Table 2).

Multiple regression analysis was performed to assess the relative impact of self-criticism, self-compassion, depression, anxiety, stress, and friendship social network (support and negative interaction) on PWB of medical students (Table 3). Results indicated that the predictor variables explained $51.51 \%$ of the variance (R-sq (adj) 49.13\%, $\mathrm{F}=21.70, \mathrm{p}=$ 0.000 ) in PWB (response variable). Among the variables only self-criticism $(\beta=-3.01, \mathrm{~T}$-value $=-2.29, \mathrm{p}=0.023)$, self- 
compassion $(\beta=8.01, \mathrm{~T}$-value $=4.66, \mathrm{p}=0.000)$, and support from friends $(\beta=3.48$, $\mathrm{T}$ value $=4.66, \mathrm{p}=0.000)$ significantly predicted PWB among medical students.

Regression equation: Psychological well-being=46.26 3.01 self-criticism +8.01 self-compassion +3.484 friendship support -0.427 Negative peer interaction -0.408 Depression +0.047 Anxiety + 0.232 Stress.

The regression equation shows that the highest impact on PWB was from self-compassion, followed by support from friendships and self-criticism in that order.

\section{DISCUSSION}

Doctors are seen as the epitome of health delivery in India and are held in high regard with a divine status by the public. Consequently, the pressure to deliver miraculous cures despite the limitations of human intellect and technological shortcomings is internalized by the medical community. Anything less than an optimal cure of a patient under treatment is viewed with scepticism, blame or neglect on the physician's part without any account of illness related factors. This places doctors under enormous occupational stress to deliver every time. To cope, doctors develop a self-critical attitude to match up to the unreasonable expectations of society. ${ }^{22}$ This, unfortunately, takes its toll on the well-being of physicians leading to compassion fatigue, work overload and burnout which in turn has detrimental effects on patient care and outcomes. ${ }^{23}$ As prevention is always better than a cure, finding the predictors of PWB in future doctors (Medical Students) is prudent. This study assumes significance as it investigates the roots of medical stress by analysing the main contributory factors i.e., self-criticism and self-compassion.

Male medical students in our study had significantly higher levels of self-criticism and lower self-compassion than their female counterparts. In a review of prospective studies on mental health problems of young doctors, Tyssen \& Valgum observed greater levels of self-criticism in young male doctors and also that it is a strong predictor for current and future episodes of depression in their careers. ${ }^{24}$

This study also found a significant negative correlation between self-criticism and PWB. This is indeed worrying, as the very trait that is taught, revered and encouraged in medical school turned out to be a significant predisposing factor for psychopathology in the lives of doctors. ${ }^{25}$ This does not mean that doctors should not be critical of their competencies. The last thing the society needs is an overconfident doctor who cannot engage in critically analysing his/her work. However, when self-criticism becomes habitual and excessive, it causes disabling levels of shame in response to professional failure. This is counterproductive as negative emotions hinder selfreflection, mature coping, optimal response and learning. ${ }^{26}$

A significant positive correlation was found between selfcompassion and PWB among medical students in this study. In addition to a poor work-life balance that is associated with personal stressors, doctors are exposed to patients' pain and suffering routinely during their training and clinical practice. ${ }^{27}$ Signs of burnout and overwork, long viewed as a sign of prestige and success is being increasingly reported to compromise clinical care delivery and affect doctor's wellbeing. ${ }^{28}$ In this context, being compassionate towards oneself is central to the caring profession. While some may be of the opinion that self-compassion hinders competence, growing evidence suggests that these two qualities go hand in hand. ${ }^{29}$ Also being self-compassionate should not be confused with self-centeredness. With self-compassion arises the insight that human nature is not perfect and all people including oneself deserves compassion.

Using regression analyses the study found that only selfcompassion, support from friends, and self-criticism (Negatively) significantly predicted the PWB of medical students. Levels of depression, anxiety, stress and negative peer interactions failed to significantly affect PWB. This illustrates the importance of self-compassion and supportive interpersonal relationships. Studies on interpersonal support and self-compassion have shown that highly selfcompassionate people have strong and stable relationships, are emotionally connected, accept and support autonomy and are less controlling, dominating and abusive. ${ }^{30}$ Thus one can hypothesize that students who are more self-compassionate and less self-critical tend to foster strong and healthy friendships during their training which can buffer to counteract loneliness, setbacks, and failures inherent to medical training. ${ }^{31-34}$ This is all the more important as most students pursuing MBBS at Sikkim Manipal Institute of Medical Sciences are away from their family and friends and need to develop interpersonal skills to initiate and maintain friendly peer relationships.

This study is not without its limitations. As it is crosssectional in nature, correlation does not necessarily imply causation. We have not explored the impact of personality traits on PWB. The study sample consisted of students from one medical college, and the inferences drawn should be generalized with caution. The strengths of the study lie in it being the first Indian study to explore the traits of selfcompassion and self-criticism in relation to PWB among medical students. By using standardized rating scales, our findings can be corroborated by future research in India.

\section{CONCLUSIONS}

Self-compassion is an integral trait that can counter pathological self-criticism that has pervaded the medical profession. Students in training need to develop more selfcompassion to enhance their resilience when faced with the challenges of a medical career. Mindfulness training has the potential to enhance self-compassion and could be formally included in the MBBS curriculum to enhance the PWB of medical students. 35

\section{REFERENCES}

[1] Firth-Cozens J. Emotional distress in junior house officers. Br Med J (Clin Res Ed) 1987;295(6597):533-6.

[2] Reuben DB. Depressive symptoms in medical house officers: effects of level of training and work rotation. Arch Int Med 1985;145(2):286-8.

[3] Gilbert P, Clarke M, Hempel S, et al. Criticizing \& reassuring oneself: an exploration of form, style \& reason in female students. Brit J Clin Psychol 2004;43(1):31-50.

[4] Blatt SJ, Zuroff DC. Interpersonal relatedness and selfdefinition: two prototypes for depression. Clin Psychol Rev 1992;12(5):527-62. 
[5] Kannan D, Levitt HM. A review of client self-criticism in psychotherapy. J Psychother Integr 2013;23(2):166-78.

[6] Blatt SJ. Experiences of depression: theoretical, clinical and research perspectives. Washington, DC: American Psychological Association 2004.

[7] Brewin CR, Firth-Cozens J. Dependency and selfcriticism as predictors of depression in young doctors. J Occupat Health Psychol 1997;2(3):242-6.

[8] Cox BJ, Fleet C, Stein MB. Self-criticism and social phobia in the US national comorbidity survey. J Affect Disord 2004;82(2):227-34.

[9] Bagby RM, Cox BJ, Schuller DR, et al. Diagnostic specificity of the dependent and self-critical personality dimensions in major depression. J Affect Disord 1992;26(1):59-63.

[10] Hedman E, Ström P, Stünkel A, et al. Shame \& guilt in anxiety disorder: effects of CBT and association with anxiety and depressive symptoms. PLoS One 2013;8(4):e61713.

[11] Wiseman H, Raz A, Sharabany R. Depressive personality styles and interpersonal problems in young adults with difficulties in establishing long-term romantic relationships. Isr J Psychiatry Rel Sci 2007;44(4):280-91.

[12] Besser A, Priel B. A multisource approach to selfcritical vulnerability to depression: the moderating role of attachment. J Pers 2003;71(4):515-55.

[13] Neff KD. The development and validation of a scale to measure self-compassion. Self and Identity 2003;2(2):223-50.

[14] Neff KD. Self-compassion: an alternative conceptualization of a healthy attitude toward oneself. Self and Identity 2003;2(2):85-101.

[15] Barnard LK, Curry JF. Self-compassion: conceptualizations, correlates and interventions. Rev Gen Psychol 2011;15(4):289-303.

[16] MacBeth A, Gumley A. Exploring compassion: a metaanalysis of the association between self-compassion and psychopathology. Clin Psychol Rev 2012;32(6):545-52.

[17] Heffernan M, Griffin QMT, McNulty SR, et al. Selfcompassion and emotional intelligence in nurses. Int J Nursing Practice 2010;16(4):366-73.

[18] Henry JD, Crawford JR. The short-form version of the Depression Anxiety Stress Scales (DASS - 21): construct validity and normative data in a large nonclinical sample. Brit J Clin Psychol 2005;44(Pt 2):22739.

[19] Ryff CD, Keyes CL. The structure of psychological wellbeing revisited. J Pers Soc Psychol 1995;69(4):719-27.

[20] Furman W, Buhrmester D. Children's perceptions of the personal relationships in their social networks. Dev Psychol 1985;21(6):1016-24.
[21] Minitab 17 Statistical Software Product Version 17.3.1: Computer software: State College, PA, USA: Minitab, Inc., 2010 (www.minitab.com).

[22] Royal College of Physicians. Doctors in society: medical professionalism in a changing world. Report of a Working Party of the Royal College of Physicians of London. London: RCP, 2005.

[23] Raab K. Mindfulness, self-compassion and empathy among health care professionals: a review of the literature. Journal of Health Care Chaplaincy 2014;20(3):95-108.

[24] Tyssen R, Vaglum P. Mental health problems among young doctors: an updated review of prospective studies. Harvard Review of Psychiatry 2002;10(3):154-65.

[25] Driessen E, Van Tartwijk J, Dornan T. The self-critical doctor: helping students become more reflective. BMJ 2008;336(7648):827-30.

[26] Dunkley DM, Zuroff DC, Blankstein KR. Specific perfectionism components versus self-criticism in predicting maladjustment. Pers Individ Dif 2006;40(4):665-76.

[27] Vachon MLS. Reflections on compassion, suffering and occupational stress. In: Malpas J, Lickiss $\mathrm{N}$, eds. Perspectives on human suffering. London: Springer 2012: p. 317-36.

[28] Mills J, Chapman M. Compassion and self-compassion in medicine: self-care for the caregiver. AMJ 2016;9(5):87-91.

[29] Cassel EJ. Compassion. In: Lopez SJ, Snyder CR, eds. Oxford Handbook of Positive Psychology. New York, NY: Oxford University Press 2009: p. 393-403.

[30] Neff KD, Beretvas SN. The role of self-compassion in romantic relationships. Self - Identity 2013;12(1):7898.

[31] Fichman L, Koestner R, Zuroff DC. Depressive styles in adolescence: assessment, relation to social functioning and developmental trends. J Youth Adolesc 1994;23(3):315-30.

[32] Mongrain M, Lubbers R, Struthers W. The power of love: mediation of rejection in roommate relationships of dependents and self-critics. Pers Soc Psychol Bull 2004;30(1):94-105.

[33] Wiseman H. Interpersonal relatedness and selfdefinition in the experience of loneliness during the transition to university. Personal Relationships 1997;4(3):285-99.

[34] Zuroff DC, Koestner R, Powers TA. Self-criticism at age 12: a longitudinal-study of adjustment. Cognit Ther and Res 1994;18(4):367-85.

[35] Sampath H, Biswas AG, Soohinda GS, et al. Mindfulness and its role in psychological well-being among medical college students. Open J Psychiatry Allied Sci 2019;10(1):52-6. 